\title{
Is It Time for Radiology to Embrace Commoditization?
}

\author{
Richard Gunderman, MD, PhD, Sean Dodson, MD \\ Department of Radiology, Indiana University, Indianapolis, Indiana
}

To defend the truth, to articulate it with humility and conviction, to bear witness to it in life.... —Pope Benedict XVI

We are not accustomed to reading, let alone responding, to most of the nonrefereed publications physicians receive on a regular basis, many sponsored by industry and now distributed primarily through electronic platforms. However, one recent article caught our eye, and after reading it with a growing mixture of disbelief and outrage, we felt compelled to respond directly to assertions we regard as illfounded and even pernicious [1].

The piece was authored by Benjamin W. Strong, MD, chief medical officer of vRad, which regularly sponsors content in the publication in question. Next to the piece is a description of vRad as "a global telemedicine company” and “the nation’s leading radiology practice with over 350 board-certified and eligible physicians.” If this is indeed the direction in which radiology is being led, we are in trouble.

The title of the piece is "Radiology Myths Reconsidered: 7 Debunked, 1—Commoditization— Confirmed.” In it, the author announces that "the time has come for the profession of radiology to embrace a label it has been furiously trying to beat back for years: commoditization. The battle against those who wield it as a pejorative is not just futile, it’s also counterproductive.”

The author claims that his opponents operate with "agendas and aims that drive some to dismiss things they don't like by labeling them commodities.” Against those who wield the term pejoratively, he argues that commoditization is "a very good thing for the consumer," denoting not only quality but also

This is the author's manuscript of the article published in final edited form as:

Gunderman, R., \& Dodson, S. (2016). Is It Time for Radiology to Embrace Commoditization? Journal of the American College of Radiology, 13(6), 754-755. http://doi.org/10.1016/j.jacr.2015.10.031 
availability and cost savings. Commodity producers, he reminds us, are frequently regulated by the government and required to meet "standards of quality that are strict, objective and non-negotiable."

He cites the example of corn, which the FDA limits in moisture content (14\%) and insect damage (which must be at least 95\% absent). Citing also the examples of wheat and beef, he goes on to "wholeheartedly endorse the term commoditization as applied to radiology.” He then adds, "That goes, with special emphasis, for its use around the branch of radiology near and dear to my heart: teleradiology."

He then expresses the hope that "all who love our profession will join me" in rejecting "the catcalls behind commoditization (as well as its frequent co-pilot in the intended-insult cockpit, ‘depersonalization').” Each of these myths, he claims, is “quite easily debunked by the facts.”

The first myth is the notion that "radiology quality can be defined in many different ways, many of which are difficult to quantify." To the contrary, he says, "Quality in radiology comes down to one thing and one thing only: interpretive accuracy.”

We believe this is false, and we offer as a counterexample the quality of relationships radiologists enjoy with referring health professionals. These have an important effect on interprofessional communication, respect, and trust, all of which can powerfully influence patient care.

The second myth the author aims to debunk is this: "Most radiology practices have adequate quality-assurance (QA) oversight.” In fact, he declares, “most practices practice QA in name only,” in part because overreads are "rarely provided by an objective third party.” In most cases, they have a “personal relationship with the radiologist they are overreading or, worse yet, some financial interest in that radiologist's practice.” 
He then goes on to cite his own practice’s QA practices, which rely on “objective, paying clients” who are "highly motivated to find errors in our work.” He concludes by saying, "If more radiology practices followed...what I'm proud to call 'commodity-level QA'...more would welcome the charge of commoditization as warmly as I do.”

Is the author, by his use of the phrase "worse yet," insinuating that financial interests impeach the credibility of physicians? It seems so. And if this is the case, what level of credibility should be granted a method for assessing accuracy that relies on the judgments of "paying clients?”

We do not believe that the fact that money changes hands necessarily undermines the credibility of professional judgments. We do, however, question whether it is fair to impugn the potential financial biases of radiology practices while promoting a point of view — and a business — in a publication sponsored by the same business.

The third myth states that teleradiologists are of lesser training and ability than on-site radiologists. The fact, states the author, is that teleradiologists "frequently have better training, deeper experience and more finely honed subspecialty skills than onsite radiologists.” But the contrary is often true: on-site radiologists frequently have better training, deeper experience, and more finely honed skills than teleradiologists.

The author alludes to the rigors he endured to obtain " 50 state licenses," including giving an account of "every step of my career from its start to the current day.” Our own experience of state licensure — admittedly not as extensive as the author's—-leads us to doubt that state licensing procedures should be relied upon as arbiters of radiologic quality.

The fourth myth states that "radiologists are valued, if not revered, by their clinical colleagues." In fact, the author asserts, "we... are still working our way out of clinicians' perception of us as either underworked and overpaid prima donnas, anti-social troglodytes—or some strange brew of both.” 
These statements simply do not comport with our experience of radiology practice. Perhaps we are the victims of mass delusion, but our relationships with referring health professionals feel strong and mutually respectful. Terms such as prima donnas and antisocial troglodytes seem to betray a coarsened appreciation for professionalism.

The fifth myth states that consultation between a radiologist and a clinician (or between radiologists) must take place in physical proximity. We are aware of no radiologist who insists that close physical proximity is a prerequisite for effective consultation. All of us have discussed cases by telephone.

But face-to-face consultation adds more. Much of communication is nonverbal, and face-to-face communication is better suited to building relationships. Radiologists are more likely to become involved in service and collaboration with colleagues and institutions when they are physically present, which helps build practices.

The sixth myth also seems a bit of a straw man: "It is impossible to develop meaningful clinical relationships in a distributed practice model.” Again, we know of no one who is using the word impossible here. The author points to a study showing that 35\% of newly married couples got acquainted online, concluding that "matchmaking has gotten happily commoditized too.”

Even in cases in which the premarital acquaintance was born online, however, we suspect that many of these couples still made efforts to meet each other and spend a substantial amount of time together before they decided to get married. This is certainly what we would hope for our own children.

The reason, of course, is that marriage is about more than getting work done. A good marriage is largely about the relationship itself, a relationship built on caring. And caring is not an attitude we normally associate with commodities, such as bushels of corn, gallons of gasoline, and pork bellies. 
The seventh myth states that "radiologists can establish their value through personal relationships with their hospital administrators and clinical colleagues,” to which the author attaches this rebuttal: "No one worth reading for is going to assign a radiologist solely on the basis of friendship.”

Again, no one is suggesting that friendship should be the exclusive basis for health care decision making, but a health care environment devoid of such relationships is an impoverished one. To treat human beings as commodities is to treat them as something that can be bought and sold and thereby to dehumanize them.

The future of radiology will be bright only if we resist the descent to the lowest common denominators of radiology practice: productivity, timeliness, and accuracy. At this level, radiologists cease to be people and become mere full-time equivalents or "bodies," as in "I need 4.5 bodies to staff my new imaging center.” The best radiologists perform well in each of these areas, but they contribute far more through the relationships they build.

The radiologist-as-commodity is not inevitable. To the contrary, it is a professional aberration, one that warrants strenuous opposition by radiologists who care about the professionalism of the field and those who practice it. We owe it to the generations of radiologists who will follow us to ensure that the practice of radiology draws as deeply as possible on a full range of human excellences, including the vital aspiration for meaningful relationships in the practice of medicine.

\section{Reference}

B. Strong. Radiology myths reconsidered: 7 debunked, 1—commoditization—confirmed. ImagingBiz (September 28, 2015) Available at: http://www.imagingbiz.com/portals/medical-imagingreview/sponsored/1065/topics/business/radiology-myths-considered-7-debunked1\%E2\%80\%94commoditization\%E2\%80\%94-confirmed Accessed November 10, 2015 